\title{
Acute poisonings presenting to King Edward VIII hospital intensive care unit in Durban, South Africa
}

\author{
R Goga, ${ }^{1} \mathrm{MB}$ ChB; OrcID 0000-0001-8050-1718; \\ K de Vasconcellos, ${ }^{2} \mathrm{MB}$ ChB, DA (SA), FCA (SA), Cert Crit Care; OrcID 0000-0002-1975-6633; \\ D Singh, ${ }^{2}$ MB ChB, FCA (SA), Cert Crit Care, MSc (Med); OrcID 0000-0002-0839-6703 \\ ${ }^{1}$ Division of Emergency Medicine, Faculty of Medicine and Health Sciences, Stellenbosch University, Cape Town, South Africa \\ ${ }^{2}$ Department of Critical Care, King Edward VIII Hospital, Durban, South Africa; Department of Anaesthesiology and Critical Care, School of Clinical \\ Medicine, College of Health Sciences, Nelson R Mandela School of Medicine, University of KwaZulu-Natal, Durban, South Africa
}

Corresponding author: R Goga (goga.raeesa@gmail.com)

\begin{abstract}
Background. Acute poisoning is a potentially preventable burden on the healthcare systems and a significant cause of morbidity and mortality worldwide. Improved knowledge of the patterns of poisoning, the clinical course and outcomes of these cases may help create better preventive and management approaches.

Objectives. To describe the demographics, clinical characteristics and outcomes of patients with acute poisonings who were admitted to a multidisciplinary intensive care unit (ICU) at King Edward VIII Hospital, Durban, South Africa.

Methods. A retrospective observational chart review of patients admitted to the study ICU with acute poisoning over a 24-month period (1 July 2015 - 30 June 2017).

Results. A total of 85 patients with acute poisoning were admitted to the ICU during the study period. There was a female preponderance (55\%) with a median age of 28 years. ICU mortality was $16.5 \%$ with a median ICU length of stay of 3 days. Tricyclic antidepressants (TCA) were the most common toxin identified (16.5\%). The ingestion of amphetamines was associated with a statistically significant increase in mortality $(100.0 \%$ v. $13.4 \%$; $p=0.04)$. Ethylene glycol was a commonly ingested toxin ( $9.4 \%$ of admissions) and had a high mortality rate of $37.5 \%$ that was not statistically significant $(p=0.121)$. Referral for inotropic support, a Glasgow Coma Scale $\leq 5$ and metabolic acidosis on admission were associated with higher ICU mortality.

Conclusion. Acute poisoning results in potentially preventable ICU admission and mortality. TCA poisoning was the most common presentation and this warrants review of TCA prescription practice. Ingestion of illicit drugs, ethylene glycol or presentation with a markedly reduced level of consciousness, shock or metabolic acidosis should alert treating physicians to a possible elevated risk of adverse outcomes.

Keywords. poisoning; intensive care; outcomes.
\end{abstract}

South Afr J Crit Care 2021:37(1):10-15. https://doi.org/10.7196/SAJCC.2021.v37i1.408

Contribution of the study. This is the first study to describe acute poisoning patterns in KwaZulu-Natal from a critical care perspective. This will increase knowledge of common toxins and the presentations that lead to critical care referral. Furthermore, prescription practices for common toxins like TCAs need to be reviewed as a prevention strategy.

Acute poisoning represents a complex public health problem, resulting in hospitalisation, utilisation of healthcare resources and mortality. ${ }^{[1]}$ According to the World Health Organization (WHO), $>000000$ people die of suicide annually and it is estimated that around $20 \%$ of global suicides are due to pesticide self-poisoning, most of which occur in rural agricultural areas in developing countries. ${ }^{[2]}$

Studies have determined a high rate of poisoning in Gauteng and Eastern Cape provinces ${ }^{[3,4]}$ but no data are available for poisonings in the critical care setting in KwaZulu-Natal (KZN) Province, which is South Africa's (SA's) second most populated province after Gauteng. ${ }^{[4,5]}$

Poisoning represents an avoidable burden on limited critical care resources in SA. In the Eastern Cape, 15 - 20\% of patients presenting with acute poisonings were admitted to a critical care unit, further straining the healthcare sector in one of SA's poorest provinces. ${ }^{[4]}$
The profile of patients and the type of toxins ingested varies between countries and between urban and rural settings. The risk factors for poisoning include systemic illnesses, psychiatric disorders, drug and alcohol abuse, interpersonal difficulties and socioeconomic problems. ${ }^{[7]}$ In the SA context, agricultural chemicals accounted for $20 \%$ of deaths in eight hospitals in Gauteng and KZN provinces. ${ }^{[8,9]}$

The King Edward VIII Hospital (KEH) ICU is a busy multidisciplinary unit in a tertiary, academic hospital in Durban, SA. Although situated in a major metropolitan area, the ICU provides critical care for patients from urban, peri-urban and rural areas throughout KZN. There is limited information regarding the poisoning patterns and critical care outcomes in this setting. The aim of the present study was to describe the demographics, clinical features, course and outcomes of all patients presenting with acute poisonings at the study ICU over a 24-month period. 


\section{Methods}

A retrospective chart review was conducted of patients admitted to KEH ICU with acute poisoning over a 24-month period (1 July 2015 - 30 June 2017).

Cases were identified from the admission register and data were extracted from the stored ICU records of patients, which included data available from the initial consultation, admission summary, ICU course and eventual ICU outcome. A total of 102 patients were admitted to the ICU with acute poisoning. Patients younger than 18 years of age and those with self-harm other than toxin ingestion were excluded from the study. A total of 85 patients were included in the study.

Patients were given a unique study number and data were captured using an electronic spreadsheet. Patient demographic data collected included age, sex and referral hospital. The type of toxin was classified as either a single specific toxin or polypharmacy (where two or more toxins were ingested). Where the toxins were known in a patient who had ingested multiple toxins (polypharmacy), the individual toxins were recorded and presented, but only single-toxin ingestions were used for comparative analysis due to the possibility of drug interactions in polypharmacy biasing the results of these analyses. The reason for referral to ICU was differentiated into inotropic support, ventilation or renal replacement therapy (RRT).

Clinical parameters collected included Glasgow Coma Scale (GCS) and whether inotropes were required or not. As most patients were intubated, GCS was recorded out of 10, with the verbal (V) score removed. Arterial blood gas (ABG) results, namely $\mathrm{pH}$, partial pressure of carbon dioxide $\left(\mathrm{pCO}_{2}\right)$, partial pressure of oxygen $\left(\mathrm{pO}_{2}\right)$, bicarbonate, base excess, lactate and oxygen saturation were captured. These ABG parameters were subsequently summarised as either normal, metabolic acidosis, metabolic alkalosis, respiratory acidosis, respiratory alkalosis and mixed acid-base disorder. The requirement for respiratory, cardiovascular or renal support in ICU and on discharge was documented. The length of stay (LoS) in the ICU, complications and ICU outcome were also recorded.

Statistical analysis was performed using SPSS software for Windows, version 25.0 (IBM Corp., USA). Categorical data were summarised as percentages and $95 \%$ confidence intervals (CI) where appropriate. Categorical data were compared using the Fisher's exact test or Pearson's $\chi^{2}$ test where appropriate. For categorical variables with $>2$ categories, where necessary, adjusted standardised residuals were calculated if the overall $p$-value for the comparison was $<0.05$. An adjusted standardised residual $<2.0$ suggests the variable of interest is less common than expected by chance $(p<0.05)$ for the outcome of interest, whereas a value $>2.0$ suggests the outcome is more common than expected by chance $(p<0.05)$. Continuous data were summarised as mean (standard deviation (SD)) when the distribution was normal or median (interquartile range (IQR)) when there was a non-normal distribution. These data were compared using independent samples $t$-test or Mann-Whitney $U$-test, respectively.

Approval to conduct this research was obtained from $\mathrm{KEH}$ and KwaZulu-Natal Department of Health Research Committee. Ethics approval was granted by the Biomedical Research Ethics Committee at the University of KwaZulu-Natal (ref. no. BE 438/17) and a waiver of informed consent was granted.

\section{Results}

A total of 102 patients were admitted to ICU with acute poisoning. Of these, 17 patients were $<18$ years of age and were excluded from the study. Thus, 85 patients were included in the study. The majority of patients were female $(55 \% ; n=47)$. The median (IQR) age of the cohort was $28(22-42)$ years. Further baseline and demographic data are provided in Table 1 .

In terms of ICU outcomes, mortality was $16.5 \%(n=14)$, with a median (IQR) ICU LoS of 3 (1 - 18) days. There was no significant difference in LoS between survivors and non-survivors. Patients were referred to the ICU for mechanical ventilation $(98.8 \%$; $n=84)$, inotropic support (25.9\%; $n=22)$ and/or RRT $(12.9 \% ; n=11)$. Males were significantly more likely to die in the ICU $(71.3 \% ; n=10 / 14 ; p=0.028)$, despite accounting for fewer admissions. Referral for inotropic support and a GCS of $\leq 5$ were associated with an ICU mortality of $36.4 \%$ v. $9.5 \%$ $(p=0.007)$ and $23.5 \%$ v. $5.9 \%$ ( $p=0.032)$, respectively. Inotropic support was initiated on transfer in eight patients and a further 13 patients were initiated on inotropic support during their stay in the ICU' thus, increasing the number of patients who received inotropic support in ICU to $50.6 \%(n=43)$. There was a significant difference in mortality rate between patients who required inotropic support in the ICU compared with those who did not require inotropic support $(p<0.001)$.

Of the 71 discharged patients, $5.6 \%(n=4)$ required ongoing airway support and another four patients required ongoing RRT. A quarter of the patients $(25.9 \% ; n=22)$ had complications that manifested in the ICU. Aspiration pneumonitis/pneumonia was the most common complication $(40.9 \%$; $n=9)$. All patients with aspiration pneumonia/ pneumonitis and those with infectious complications were discharged from ICU. There was a significant difference in mortality between the different complications $(p<0.001)$. The adjusted standardised residual for cardiac arrest and death was 4.0 and was 2.2 for acute respiratory distress syndrome (ARDS) and death, while the values for other complications and death were all between -2 and 2 . This suggests that patients who suffered a cardiac arrest or developed ARDS were significantly more likely to die than those that developed other complications.

Almost half of the patients $(48.2 \% ; n=41)$ presented with a metabolic acidosis (Table 2). A lower $\mathrm{pH}(p=0.028)$ and negative base excess $(p=0.021)$ were significantly associated with ICU mortality (Figs 1 and 2 ).

The toxin was known in 70 patients and 103 different toxins were identified (Table 3). The toxin was not known in $17.6 \%(n=15)$ of the patients, of whom $13.3 \%(n=2)$ died and $86.7 \%(n=13)$ survived.

Table 4 shows the ICU outcome by toxin for the 43 patients in whom a single known toxin was ingested. This excluded patients who had ingested multiple toxins or where the toxin was unknown. Tricyclic antidepressants (TCA) were the most common single toxin identified and accounted for $20.9 \%(n=9)$ of identified toxins. There was a statistically significant difference $(p=0.042)$ in outcomes between patients who ingested different single identified toxins (Table 4).

Additional analyses were performed to compare the impact of toxins on outcome, even when ingested as part of a polypharmacy. In this case, a patient who had ingested the toxin of interest was included in the analysis even if other toxins were ingested and the comparator was all patients not known to have ingested that toxin. Only the ingestion of illicit drugs was associated with a statistically significant increase in mortality when compared with all other toxins $(p=0.023)$. This increased mortality appears to be driven by a high mortality associated with amphetamine ingestion. All three patients who were known to have ingested amphetamines died (mortality rate 100\%), and patients not known to have ingested amphetamines $(n=11 / 82)$ had a mortality rate of $13.4 \%$. The mortality rate for ethylene glycol poisoning was $37.5 \%(n=3 / 8)$ as opposed to $14.3 \%(n=11 / 77)$ for patients who were not known to have ingested ethylene glycol $(p=0.121)$. Poisoning with both illicit drugs and ethylene glycol was more common in males $(87.5 \% ; n=7 / 8)$ as opposed to all other toxins $(40.3 \%$; $n=31 / 77)$. 
Table 1. Demographic and clinical characteristics of patients who were admitted to ICU $(N=85)$

\begin{tabular}{|c|c|c|c|c|}
\hline \multirow[b]{2}{*}{ Variable } & \multirow[b]{2}{*}{$\begin{array}{l}\text { Overall sample } \\
(n=85), n(\%)^{*}\end{array}$} & \multicolumn{2}{|c|}{ ICU outcome } & \multirow[b]{2}{*}{$p$-value } \\
\hline & & $\begin{array}{l}\text { Died } \\
(n=14), n(\%)^{*}\end{array}$ & $\begin{array}{l}\text { Discharged } \\
(n=71), n(\%)^{*}\end{array}$ & \\
\hline Age (years), median (IQR) & $28(22-42)$ & $31(28-42)$ & $28(21-42)$ & 0.322 \\
\hline \multicolumn{5}{|l|}{ Gender } \\
\hline Female & $47(55.3)$ & $4(28.6)$ & $43(60.6)$ & 0.028 \\
\hline Male & $38(44.7)$ & $10(71.4)$ & $28(39.4)$ & \\
\hline \multicolumn{5}{|l|}{ Level of referral hospital } \\
\hline District/clinic & $28(32.9)$ & $3(21.4)$ & $25(35.2)$ & 0.556 \\
\hline Regional & $39(45.9)$ & $8(57.1)$ & $31(43.7)$ & \\
\hline Tertiary & $18(21.2)$ & $3(21.4)$ & $15(21.2)$ & \\
\hline Referral for mechanical ventilation & $84(98.8)$ & $14(100)$ & $70(98.6)$ & 0.547 \\
\hline Referral for inotropic support & $22(25.9)$ & $8(57.1)$ & $14(19.7)$ & 0.007 \\
\hline Referral for RRT & $11(12.9)$ & $4(28.6)$ & $7(9.9)$ & 0.078 \\
\hline Referral GCS, median (IQR) & $5(2-7)$ & $2(2-5)$ & $5(2-7)$ & 0.046 \\
\hline Referral GCS $\leq 5$ & $51(60.0)$ & $12(85.7)$ & $39(54.9)$ & 0.032 \\
\hline Inotropic support on admission & $30(35.3)$ & $8(57.1)$ & $22(31.0)$ & 0.073 \\
\hline Mechanical ventilation in ICU & $83(97.6)$ & $14(100)$ & $69(97.2)$ & 0.393 \\
\hline Inotropic support in ICU & $43(50.6)$ & $14(100)$ & $29(40.8)$ & $<0.001$ \\
\hline RRT in ICU & $14(16.5)$ & $3(21.4)$ & $11(15.5)$ & 0.693 \\
\hline LoS in ICU, median (IQR) & $3(1-18)$ & $3(1-14)$ & $3(1-18)$ & 0.323 \\
\hline Complications in ICU & $22(25.9)$ & $4(28.6)$ & $18(25.4)$ & 0.750 \\
\hline Complications in ICU (breakdown) & & & & $<0.001$ \\
\hline ARDS & $1(4.5)$ & $1(25.0)$ & 0 & \\
\hline Aspiration pneumonitis/pneumonia & $9(40.9)$ & 0 & $9(50.0)$ & \\
\hline Cardiac arrest & $3(13.6)$ & $3(75.0)$ & 0 & \\
\hline Healthcare-associated pneumonia & $5(22.7)$ & 0 & $5(27.8)$ & \\
\hline Other nosocomial infection & $4(18.2)$ & 0 & $4(22.2)$ & \\
\hline \multicolumn{5}{|c|}{ Airway support still required on discharge } \\
\hline T-piece & $1(1.2)$ & 0 & $1(1.4)$ & 0.478 \\
\hline Tracheostomy & $3(3.5)$ & 0 & $3(4.2)$ & \\
\hline RRT still required on discharge & $4(4.7)$ & 0 & $4(5.6)$ & 0.224 \\
\hline
\end{tabular}

Table 2. Admission biochemical data for the entire cohort

\begin{tabular}{|c|c|c|c|c|}
\hline & Entire cohort $(n=85), n(\%)^{*}$ & $\operatorname{Died}(n=14), n(\%)^{*}$ & Discharged $(n=71), n(\%)^{*}$ & $p$-value \\
\hline \multicolumn{5}{|l|}{ Arterial blood gas } \\
\hline Normal & $28(32.9)$ & $1(7.1)$ & $27(38.0)$ & 0.116 \\
\hline Metabolic acidosis & $41(48.2)$ & $11(78.6)$ & $30(42.3)$ & \\
\hline Mixed acid-base disorder & $10(11.8)$ & $2(14.3)$ & $8(11.3)$ & \\
\hline Respiratory acidosis & $4(4.7)$ & 0 & $4(5.6)$ & \\
\hline Metabolic alkalosis & $1(1.2)$ & 0 & $1(1.4)$ & \\
\hline Respiratory alkalosis & $1(1.2)$ & 0 & $1(1.4)$ & \\
\hline pH, median (IQR) & $7.3(7.23-7.41)$ & $7.23(7.19-7.30)$ & $7.32(7.25-7.42)$ & 0.028 \\
\hline $\mathrm{pCO}_{2}$, median (IQR) & $5.1(4.31-6.00)$ & $5.2(3.10-6.00)$ & $5.1(4.40-6.00)$ & 0.545 \\
\hline $\mathrm{pO}_{2}$, median $(\mathrm{IQR})$ & $20(11.30-30.00)$ & $18.2(11.10-29.60)$ & $21.5(11.30-31.90)$ & 0.740 \\
\hline Bicarbonate, median (IQR) & $20(16.00-24.00)$ & $17(12.50-23.70)$ & $21(16.00-24.10)$ & 0.068 \\
\hline Base excess, median (IQR) & $-6.1(-11.00--0.70)$ & $-12.1(-13.50--7.00)$ & $-3.3(-9.20--0.30)$ & 0.021 \\
\hline Lactate, median (IQR) & $2(1.00-5.60)$ & $3.3(1.60-6.30)$ & $1.7(1.00-5.60)$ & 0.426 \\
\hline
\end{tabular}

\section{Discussion}

Acute poisoning is a common presentation to the emergency department and the associated morbidity and mortality is a major public healthcare issue in many countries. ${ }^{[11]}$ In SA, suicide accounts for $9.6 \%$ of all unnatural deaths, and self-poisoning is the most common method after hanging and firearm injuries. ${ }^{[12]}$ Unemployment, lack of psychiatric 


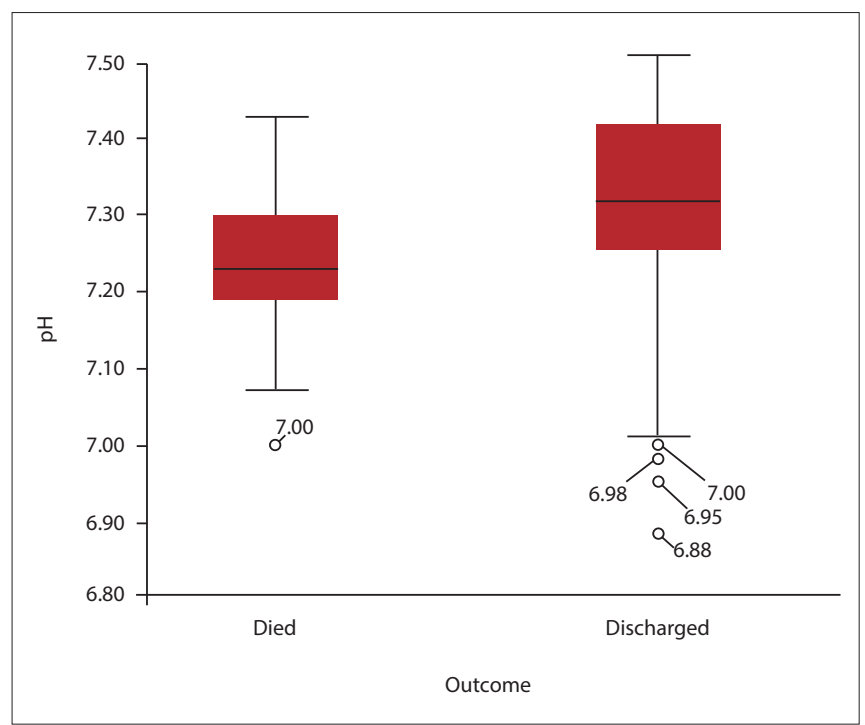

Fig. 1. Boxplot of pH on admission by ICU outcome.

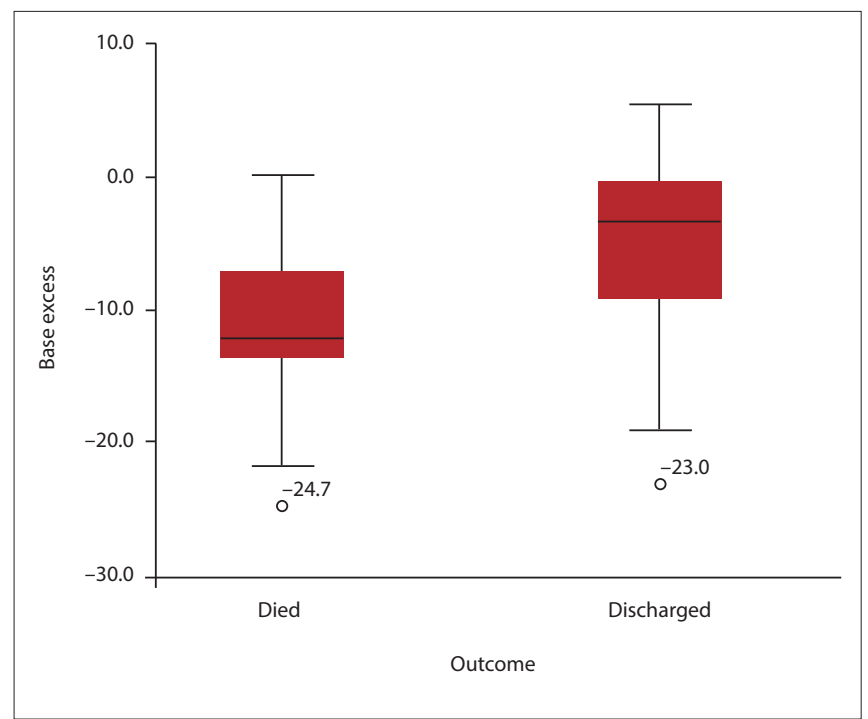

Fig. 2. Boxplot of base excess on admission by ICU outcome.

services in certain communities, poor availability of healthcare and a heavy burden of HIV are some of the potential reasons for the increasing number of acute poisonings in SA. ${ }^{[13,14]}$

We have presented data for a particularly ill cohort of patients who required organ support in a tertiary ICU and could thus be reasonably assumed to represent a subset of patients who were at high risk of mortality. As a tertiary referral unit, the study ICU received patients from all levels of hospitals in the public sector. Of note, $32.9 \%$ of patients were referred directly from district hospitals (Table 1). This highlights the importance of doctors at district levels of care being able to stabilise and refer critically ill patients appropriately. There was no difference in mortality between patients referred from different levels of care. This may be due to a relatively uniform standard of care between different institutions, or less likely, may reflect differing severity of illness on presentation to the base hospital masking differences in standard of care, or that initial stabilisation and transfer have little impact on ICU survival.

All but one patient in our study required mechanical ventilation (MV), more than half required inotropic support and $16.4 \%$ required RRT. We included all patients who were critically ill and required one or more forms of organ support. The ICU admission criteria are not
Table 3. Identified toxins $(n=103)$

\begin{tabular}{ll}
\hline Toxin category/poison & $\boldsymbol{n}(\%)$ \\
\hline Antidepressants & $20(19.4)$ \\
Tricyclic antidepressants & $17(16.5)$ \\
SSRIs & $3(2.5)$ \\
Antiepileptics & $15(14.6)$ \\
Carbamazepine & $8(7.8)$ \\
Valproate & $7(6.8)$ \\
Anti-infectives & $12(11.7)$ \\
ARVs & $4(3.9)$ \\
Bactrim & $1(0.8)$ \\
INH & $7(6.9)$ \\
Analgesics & $10(9.7)$ \\
Gabapentin & $1(1.0)$ \\
NSAIDs & $2(1.9)$ \\
Paracetamol & $1(1.0)$ \\
Pregabalin & $1(1.0)$ \\
Tramadol & $5(4.9)$ \\
Ethylene glycol & $8(7.8)$ \\
Illicit drugs & $8(7.8)$ \\
Amphetamines & $3(2.9)$ \\
Mixed illicit drugs & $5(4.9)$ \\
Organophosphates & $6(5.8)$ \\
Amitraz & $6(5.8)$ \\
Antihypertensives & $5(4.9)$ \\
Betablockers & $2(1.9)$ \\
Enalapril & $1(0.8)$ \\
HCT & $1(0.8)$ \\
Hydralazine & $1(0.8)$ \\
Sedatives/anxiolytics & $4(3.9)$ \\
Benzodiazepines & $3(2.9)$ \\
Zopiclone & $1(1.0)$ \\
Baclofen & $2(1.9)$ \\
Corrosive liquid & $2(1.9)$ \\
Antipsychotics & $4(0.3)$ \\
Chlorpromazine & $1(1.0)$ \\
Clozapine & $1(1.0)$ \\
Quetiapine & $1(1.0)$ \\
Risperidone & $1(1.0)$ \\
Methadone & $1(0.8)$ \\
SSRIs=selective serotonin reuptake inhibitors; ARVs = antiretrovirals; INH $)$ isoniazid; \\
NSAIDs =non-steroidal anti-inflammatory drugs; HCT = hydrochlorothiazide. \\
\end{tabular}

Table 4. Toxin data v. ICU outcome where a single, known toxin was ingested $(n=43)$

\begin{tabular}{|c|c|c|c|c|}
\hline \multirow[b]{2}{*}{ Toxin } & \multirow[b]{2}{*}{$\begin{array}{l}\text { Entire } \\
\text { cohort, } \\
n(\%)\end{array}$} & \multicolumn{2}{|c|}{ ICU outcome } & \multirow[b]{2}{*}{$p$-value } \\
\hline & & $\begin{array}{l}\text { Died } \\
(n=10), \\
n(\%)\end{array}$ & $\begin{array}{l}\text { Discharged } \\
(n=33), \\
n(\%)\end{array}$ & \\
\hline TCA & $9(20.9)$ & $1(10.0)$ & $8(24.2)$ & 0.042 \\
\hline Ethylene glycol & $8(18.6)$ & $3(30.0)$ & $5(15.2)$ & \\
\hline Organophosphate & $6(14.0)$ & 0 & $6(18.2)$ & \\
\hline Amitraz & $6(14.0)$ & 0 & $6(18.2)$ & \\
\hline INH & $5(11.6)$ & $1(10.0)$ & $4(12.1)$ & \\
\hline Carbamazepine & $4(9.3)$ & $1(10.0)$ & $3(9.1)$ & \\
\hline Amphetamines & $2(4.7)$ & $2(20.0)$ & 0 & \\
\hline Corrosive liquid & $2(4.7)$ & $1(10.0)$ & $1(3.0)$ & \\
\hline Sodium valproate & $1(2.3)$ & $1(10.0)$ & 0 & \\
\hline
\end{tabular}


uniform across hospitals, and previous studies have included a mixed cohort of patients not necessarily requiring organ support. Previous studies have shown that MV was required in $31-60 \%$ of patients, ${ }^{[1,10,15]}$ inotropic support in $15 \%$ of patients ${ }^{[15]}$ and RRT in $3 \%$ of patients. ${ }^{[10]}$

Demographic statistics vary between countries and between urban and rural settings. The majority of our patients were young, with a median age of 28 years and a female predominance, which was similarly demonstrated in other local studies in SA. ${ }^{[4,15]}$ However, the predominance differed globally depending on the poisoning patterns in the region and whether the study was conducted in a developing ${ }^{[1,6]}$ or developed country. ${ }^{[10,16]}$ Our cohort consisted of $44.7 \%$ males, and $71.4 \%$ of these patients died. This finding lends some support to the gender paradox in suicide, where females have higher rates of suicidal ideation and behaviour than males, but mortality from suicide is typically lower for females than for males. ${ }^{[6,16,17]}$ This trend is multifactorial and relates to health-seeking behaviours in males, greater socioeconomic burden and easy accessibility to fatal substances. ${ }^{[19,20]}$ The female predominance was less than we expected and may represent a changing demographic in terms of toxin ingestion but may also be a reflection of the paradox described above, with males being more likely to require critical care.

Mortality from acute poisoning is related to the type of toxin ingested, time to presentation and the initial management of patients in emergency centres. The mortality rate in the present study was $16.5 \%$. Other studies conducted in similar settings have found ICU-related mortality rates between $10-18 \%$, correlating reasonably well with our findings. ${ }^{[6,21]}$ Institutions in developed countries have low mortality rates of between $2-3 \% .^{[10,22]}$ This may be due to differences in medical care, delays in accessing medical care in developing countries or differences in ICU admission criteria, with developed countries being able to admit patients with lower severity of illness into ICU. ${ }^{[23]}$

This study showed that mortality rates are influenced by a patient's clinical and biochemical profile on admission to ICU. Specific factors associated with mortality in previous studies include a low GCS, acidosis, the need for MV and inotropic support. ${ }^{[6,22,23]}$ Similarly, we found that a low GCS $(p=0.046)$, metabolic acidosis $(p=0.021)$ and the need for inotropes $(p=0.007)$ were all significantly associated with mortality. While the need for inotropic support is generally accepted as a clear marker of severity and prompts referral to an ICU, our finding suggests that a low GCS and/or metabolic acidosis should also identify patients at a higher risk of death and who may need more intensive monitoring and/or earlier referral to the ICU. However, we also demonstrated that ICU survival is possible even in patients with extreme $\mathrm{pH}$ or base deficit. This highlights that single biochemical values should not be used in isolation for prognosis in this group of patients.

The ICU LoS of 3 days was similar to that reported in other studies conducted in developing countries. ${ }^{[1,6]}$ A study from the Eastern Cape, which looked at the burden of deliberate self-harm in the critical care unit reported a similar mean LoS of 79.32 hours. ${ }^{[4]}$ A Finnish $^{[16]}$ study looked at the risk factors for a prolonged ICU stay in a multivariate analysis and they concluded that renal dysfunction, respiratory failure and lowered platelet count within the first 24 hours of intensive care admission are risk factors for prolonged ICU stay.

In Switzerland, it was found that clinically relevant aspiration pneumonia/pneumonitis was a frequent complication in a cohort of consecutive overdose patients admitted to the ICU. ${ }^{[25]}$ A lower GCS on admission was an independent risk factor for aspiration pneumonia. ${ }^{[25]}$ We also obtained a similar finding in our study, where aspiration pneumonia/pneumonitis accounted for $40.9 \%$ of complications. Other infectious complications, which were identified in our study had a good outcome, illustrating the need for early identification of pathogens and appropriate treatment protocols initiated in the ICU.

The toxicological profile of patients presenting to emergency centres in SA has been documented. ${ }^{[9,26]}$ The poisoning profile in ICU and in KZN specifically, has been under-explored. As the study ICU is a major provincial referral ICU, the findings are likely to be representative of the spectrum of poisoned patients requiring intensive care but may not represent the toxicology of poisoning in the community at large. However, they do highlight toxins that are responsible for serious public healthcare concerns.

TCAs were the most common toxins that were identified in $20.0 \%$ ( $n=17 / 85)$ of the patients, and TCAs were ingested as a polypharmacy in $47.1 \%(n=8)$ of these cases. TCA overdose has been a common feature in data from the early 1990s up to more recent studies in both developed and developing countries. ${ }^{[10,22,27]} \mathrm{A}$ study conducted in the Eastern Cape ${ }^{[28]}$ looking at the burden of drug overdose in critical care units found that $29.8 \%$ of ICU admissions were due to TCA ingestion. The local and international findings are in keeping with our results of a high incidence of TCA ingestion but a low mortality rate. In SA, TCAs are widely prescribed at primary care facilities as adjuncts in pain management to treat depression and migraines.

Ethylene glycol was the second most commonly encountered toxin in this cohort $(9.4 \% ; n=8)$ and in all these cases, it was the only toxin that was ingested. Ethylene glycol poisoning showed a marked male predominance $(87.5 \%)$. The mortality rate from ethylene glycol poisoning was $37.5 \%$ as opposed to $14.3 \%$ for the rest of the cohort $(p=0.121)$. Of the eight patients with ethylene glycol poisoning, $62.5 \%(n=5)$ required RRT and constituted $35.7 \%$ of the patients who required RRT. The local literature on ethylene glycol poisoning is scarce. There has been only one published case report of ethylene glycol ingestion stating the clinical presentation and management principles. ${ }^{[29]}$ A retrospective German study ${ }^{[30]}$ analysed six cases of ethylene glycol ingestion over a 12-year period. All patients required RRT as initial management and were all discharged successfully. They concluded that without rapid recognition and early treatment with intravenous ethanol, mortality from ethylene glycol ingestion is high. ${ }^{[30]}$ Given the relative frequency of ethylene glycol poisoning in our cohort, it should be ensured that treating physicians receive appropriate medical education on this topic.

Pesticide poisoning is a major cause of death associated with poisoning in rural and agricultural areas. ${ }^{[1,6]}$ A study conducted in a critical care unit in a peri-urban hospital in the Eastern Cape identified pesticide poisoning as responsible for $55 \%$ of admissions from deliberate self-harm. ${ }^{[4]}$ In our study, the admission rate was $28.6 \%$ in patients with a single identified toxin and $14.1 \%$ in all patients. This may reflect specific regional differences in poisoning patterns in SA or may simply be a reflection of the greater urbanisation of the main drainage areas in the study ICU.

Isoniazid (INH) is used as a prophylaxis to prevent tuberculosis in HIV-positive individuals. We identified $4.9 \%(n=5)$ of patients with INH poisoning who required ventilatory support due to resistant status epilepticus. Initial management is the use of high-dose pyridoxine via the nasogastric route. ${ }^{[31]}$ RRT was not utilised in our cohort of patients with INH overdose but may have a role in severe cases not responding to pyridoxine. 


\section{Study limitations}

An inherent limitation of this study was that it was a retrospective chart review. The small cohort size and a low mortality rate may have led to an increased risk of type 2 statistical errors. The study was conducted in a single centre, which may limit external validity. This is however counterbalanced by the fact that the study was conducted in a busy referral ICU with a wide referral area. Our cohort of patients were critically ill and represented only those warranting critical care. Therefore, the patterns of poisonings cannot be generalised to the patterns experienced in the emergency centres. We excluded 17 patients from the study because they were younger than 18 years of age. Although these patients were not included in the study, this highlighted the burden of acute poisoning in adolescence. Future studies would need to include both adult and paediatric patients.

\section{Conclusion}

Acute poisoning leads to potentially preventable ICU admissions and mortality. TCA poisoning was the most common presentation and this warrants review of TCA prescription practice. Ethylene glycol poisoning was also common, occurred mostly in males and was associated with a high mortality rate. An increase in ICU mortality was noted in patients presenting with a GCS of $\leq 5$, inotropic support or a metabolic acidosis. While patients who required ICU care represent only a small portion of total admissions, this study highlights common toxins associated with ICU admission and potential risk factors for adverse outcomes. Medical practitioners treating this vulnerable group of patients should be knowledgeable in the common toxins that lead to critical care referral and should be able to identify patients at increased risk of adverse outcomes and manage them accordingly.

\section{Declaration. None.}

\section{Acknowledgements. None.}

Author contributions. KdV, RG and DS conceptualised the study and wrote the manuscript. RG acquired the data and KdV analysed and interpreted the data. All authors read and approved the final version of the manuscript for publication.

Funding. None.

Conflicts of interest. None.

1. Zinhi S, Edvin P, Aurel D. Early clinical outcomes of acute poisoning cases treated in intensive care unit. Med Arch 2015;69(4):400-409. https://doi.org/10.5455/medarh.2015.69.400-404

2. World Health Organization (WHO). Suicide. Geneva: WHO, 2019. https://www.who.int/newsroom/fact-sheets/detail/suicide (accessed 6 September 2020).

3. Kallenbach S, Bagg J, Feldman P. Experience with acute poisoning in an intensive care unit a review of 103 cases. S Afr Med J 1981;59(17):587-589.

4. Favara D. The burden of deliberate self-harm on the critical care unit of a peri-urban referral hospital in the Eastern Cape: A 5-year review of 419 patients. S Afr Med J 2013;103(1):40-43. https://doi.org/10.7196/samj.6231

5. Statistics South Africa (Stats SA). Census in brief. Pretoria: Stats SA, 2011. http://www.statssa.gov. za/census/census_2011/census_products/Census_2011_Census_in_brief.pdf
6. Ahuja H, Mathai AS, Pannu AR. Acute poisonings admitted to a tertiary level intensive care unit in northern India: Patient profile and outcomes. J Clin Diagn Res 2015;9(10):1-4. https:// doi.org/10.7860\%2FJCDR\%2F2015\%2F16008.6632

7. Mars B, Burrows S, Hjelmeland H, Gunnell D . Suicidal behaviour across the African continent: A review of the literature. BMC Public Health 2014;(14):606. https://doi.org/10.1186/1471 2458-14-606

8. Sustainable Competitiveness Observatory (SCO). (accessed 2020 Dec 12). https://competitivite. ferdi.fr/en/countries/upper-middle-income-countries

9. Malangu N, Ogunbanjo GA. A profile of acute poisoning at selected hospitals in South Africa S Afr J Epidemiol Infect 2009;24(2):14-16. https://doi.org/10.1080/10158782.2009.11441343

10. Lam S, Lau AC, Yan W. Over 8 years' experience on severe acute poisoning requiring intensive care in Hong Kong, China. Hum Exp Toxicol 2010;29(9):757-765. https://doi. org/10.1177/0960327110361753

11. Murray CJL, Lopez AD. The global burden of disease: A comprehensive assessment of mortality and disability from diseases, injuries and risk factors in 1990 and projected to 2020 . Boston: Harvard School of Public Health, 1996. https://apps.who.int/iris/handle/10665/41864 (accessed 16 January 2020)

12. Bantjes J, Kagee A. Epidemiology of suicide in South Africa: Setting an agenda for future research. S Afr J Psychol 2013;43:238-251.

13. Burrows S, Vaez M, Laflamme L. Sex-specific suicide mortality in the South African urban context: The role of age, race, and geographical location. Scand J Public Heal 2007;35(2):133139. https://doi.org/10.1080\%2F14034940600975773

14. Meehan SA, Broom Y. Analysis of a national toll free suicide crisis line in South Africa. Suicide Life Threat Behav 2007;37(1):66-78. https://doi.org/10.1521/suli.2007.37.1.66

15. Koegelenberg CFN, Joubert ZJ, Irusen EM. Tricyclic antidepressant overdose necessitating ICU admission. S Afr Med J 2012;102(5):293-294. https://doi.org/10.7196/samj.5300

16. Liisanantti J, Ohtonen P, Kiviniemi O. Risk factors for prolonged intensive care unit stay and hospital mortality in acute drug-poisoned patients: An evaluation of the physiologic and laboratory parameters on admission. J Crit Care 2011;26(2):160-165. https://doi.org/10.1016/j. jcrc.2010.08.009

17. Canetto SS, Sakinofsky I. The gender paradox in suicide. Suicide Life Threat Behav 1998;28(1):1-23.

18. Tsirigotis K, Gruszczynski W, Tsirigotis M. Gender differentiation in methods of suicide attempts. Med Sci Monit 2011;17(8):65-70. https://doi.org/10.12659\%2FMSM.881887

19. Glatstein M, Garcia-Bournissen F, Scolnik D, Koren G. Sulfonylurea intoxication at a tertiary care paediatric hospital. Can J Clin Pharmacol 2010;17:51-56.

20. Chowdary AN, Banerjee S, Brahma A, Biswas MK. Pesticide poisoning in nonfatal, deliberate self-harm: A public health issue. Indian J Psychiatry 2007;49:117-120. https://doi. org/10.4103\%2F0019-5545.33259

21. Cengiz M, Baysal Z, Ganidagli S, Altindag A. Characteristics of poisoning cases in adul intensive care unit in Sanliurfa, Turkey. Saudi Med J 2006;27(4):497-502.

22. Henderson A, Wright M, Pond SM. Experience with acute overdose patients admitted to an intensive care unit over six years. Med J Aust 1993;158:28-30. https://doi org/10.5694/j.1326-5377.1993.tb121644.x

23. Mehrpour O, Akbari A, Jahani F, et al. Epidemiological and clinical profiles of acute poisoning in patients admitted to the intensive care unit in eastern Iran (2010 to 2017). BMC Emerg Med 2018;18(1):1-9. https://doi.org/10.1186\%2Fs12873-018-0181-6

24. Mathai A, Bhanu MS. Acute aluminium phosphide poisoning: Can we predict mortality? Indian J Anaesth 2010;54(4):302-307. https://doi.org/10.4103\%2F0019-5049.68372

25. Christ A, Arranto CA, Schindler C, et al. Incidence, risk factors, and outcome of aspiration pneumonitis in ICU overdose patients. Intensive Care Med 2006;32(9):1423-1427. https://doi. org/10.1007/s00134-006-0277-4

26. Van Hoving DJ, Hunter LD, Gerber RJ, Lategan HJ, Marks CJ. The burden of intentional selfpoisoning on a district-level public hospital in Cape Town, South Africa. African J Emerg Med 2018;8(3):79-83. https://doi.org/10.1016/j.afjem.2018.03.002

27. Athavale V, Green C, Lim KZ, Wong C, Tiruvoipati R. Characteristics and outcomes of patients with drug overdose requiring admission to intensive care unit. Australas Psychiatry 2017;25(5):489-493. https://doi.org/10.1177/1039856217706824

28. Rowe K. The burden of drug overdose on critical care units in East London, South Africa. S Afr Med J 2016;106(3):227-228. https://doi.org/10.7196\%2FSAMJ.2016.v106i3.9933

29. Borkum M, Kropman A. Ethylene glycol poisoning: A case report. Continuing Med Edu 2012; $31(2)$

30. Latus J, Kimmel M, Alscher MD, Braun N. Ethylene glycol poisoning: A rare but life-threatening cause of metabolic acidosis - a single-centre experience. Clin Kidney J 2012;5(2):120-123. https://doi.org/10.1093/ckj/sfs009

31. Stead DF, Mason CR. Three cases of intentional isoniazid overdose - a life-threatening condition. S Afr Med J 2016;106(9):891-892. https://doi.org/10.7196/samj.2016.v106i9.10582

Accepted 8 January 2021. 